\section{Forschungspreis der AG Keramik geht an interregionales Autorenteam}

Seit dem Jahr 2000 stiftet die Arbeitsgemeinschaft für Keramik in der Zahnheilkunde alljährlich den „Forschungspreis Vollkeramik“ für innovative Arbeiten, die von Zahnärzten, Wissenschaftlern, Doktoranden und interdisziplinären Teams aufgrund der Ausschreibung eingereicht werden. In den vergangenen Jahren wurden Autoren ausgezeichnet, deren Themen vielfach Eingang in den Therapiekanon der Zahnmedizin gefunden haben.

In diesem Jahr wurde der Forschungspreis der AG Keramik dem Autorenteam Dr. Uwe Blunck, Zahnärztin Sabine Fischer, Dr. Jan Hajto und Prof. Roland Frankenberger für die Arbeit „Einfluss von Präparationsformen und Schichtdicke auf Bruchfestigkeit und Randverhalten von Keramikveneers" zuerkannt. Die Arbeitsteilung und Zusammenarbeit der Autoren erfolgte interregional. So wurden die Präparationen, die Herstellung der Veneers mit der adhäsiven Befestigung in München durchgeführt, die Testungen im Kausimulator sowie die Auswertung der Daten erfolgten in der Berliner Charité; die wissenschaftliche Interpretation der Vorgehensweise und der Ergebnisse fand in Marburg statt.

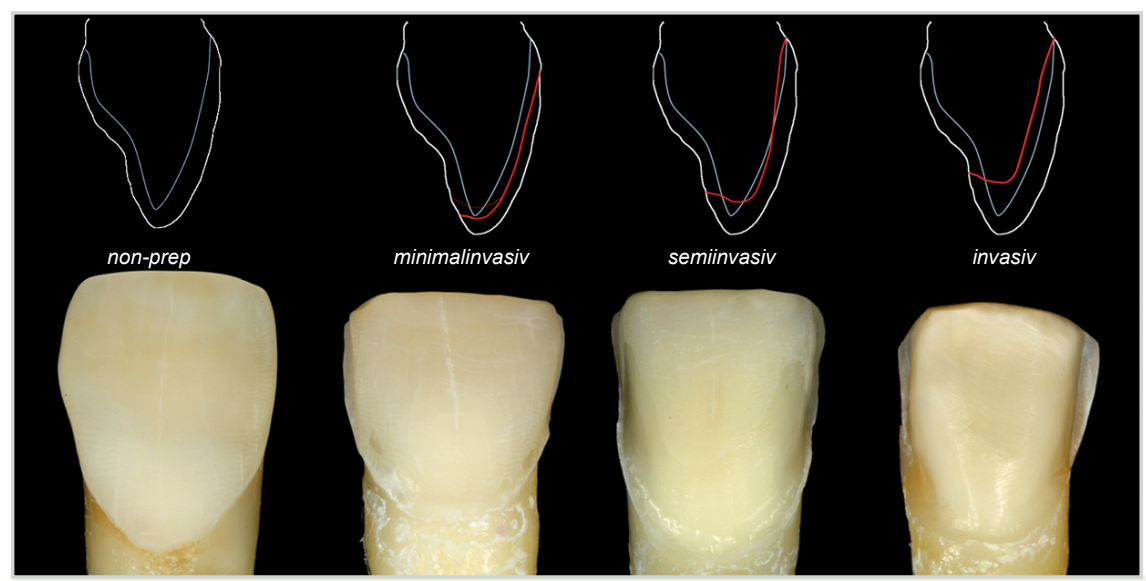

Abb. 1 Die 4 verschiedene Präparationsformen an einem oberen mittleren Schneidezahn: (v. I. n. r.) Non-Prep, minimalinvasiv, semiinvasiv, invasiv.
Adhäsiv befestigte, rein schmelzgetragene labiale Keramik-Veneers sind eine klinisch bewährte Restaurationsform. Die Verwendung von Adhäsiven, die im Dentin retentiv wirken, ist heute technisch möglich, um Keramikschalen partiell oder vollständig auch im Dentin zu verankern. Dabei ist aus grundsätzlichen Erwägungen heraus vorteilhaft, bei der Präparation möglichst große Schmelzareale zu erhalten, weil der Schmelz geätzt, konditioniert und somit ein optimaler Bindungspartner ist und die Schmelz-Dentin-Grenze aus biomechanischer Sicht ein stabilisierendes Element natürlicher Zähne darstellt. Deshalb ist es für den Behandler eine relevante Frage, ob es vorteilhaft ist, möglichst viel Zahnschmelz zu erhalten, auch wenn dies zulasten der Materialstärke, der Ästhetik und der späteren Zahn-

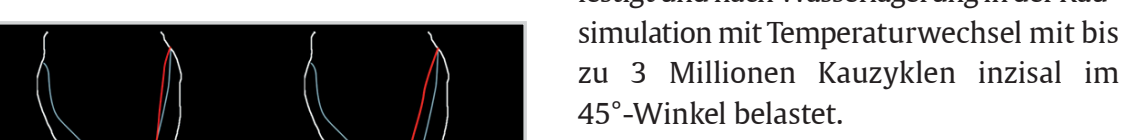

\section{Dünne Veneers im Dentin mit höherem Frakturrisiko $\nabla$}

Das Ergebnis zeigte nach 3 Millionen Zyklen, teilweise mit 100N Belastung, für alle Gruppen sehr hohe Überlebensraten. Der Medianwert der Randanalyse für den „kontinuierlichen Rand“ lag zwischen 95 und $82 \%$. Keine Unterschiede gab es weder am Übergang Keramik/Befestigungskomposit noch am Übergang zur Zahnhartsubstanz. Dennoch - das Frakturrisiko ist 

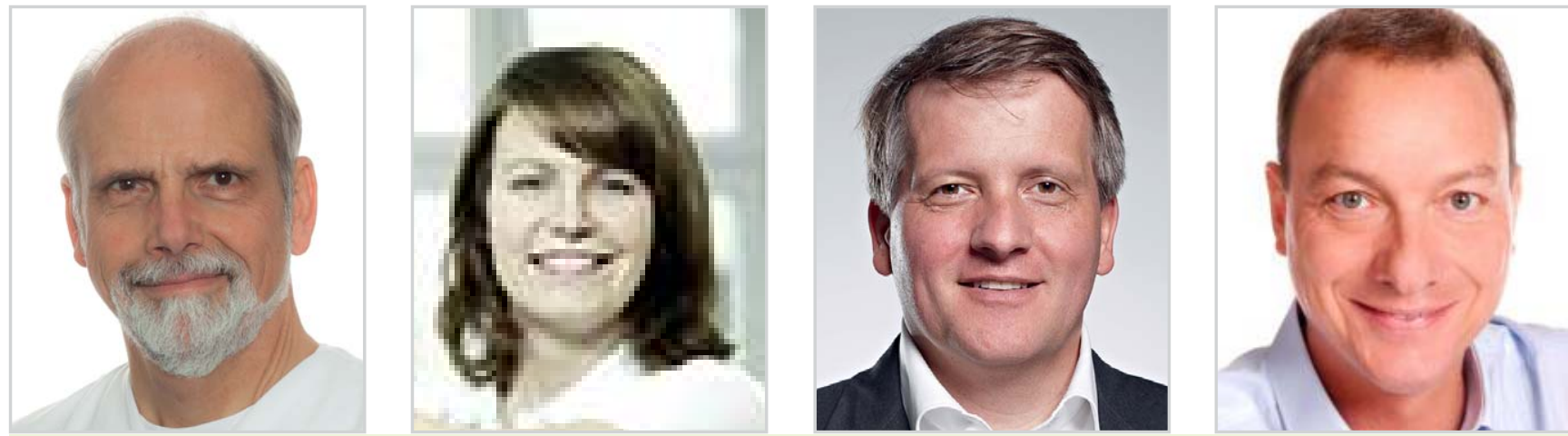

Abb. 3 Das Preisträger-Team: (v. I. n. r.) Dr. Uwe Blunck, Berlin; ZA Sabine Fischer, Berlin; Dr. Jan Hajto, München; Prof. Roland Frankenberger, Marburg

signifikant höher bei dünnen Veneers mit Präparationen vollständig oder partiell im Dentin. Besser schnitten Veneers ab, deren Präparation vollständig von Schmelz umschlossen waren. Keinen Einfluss hatten Kompositrestaurationen, weder auf das Randverhalten noch auf die Frakturgefährdung der Veneers.
Neben der Präsentation der prämierten Studie durch die Autoren erfolgt die Übergabe des 15 . Forschungspreises an das Autorenteam auf dem Deutschen Zahnärztetag am 6. November 2015 in Frankfurt/ Main. Die Laudation wird Dr. Bernd Reiss, Mitglied des Vorstands der DGZMK und 1. Vorsitzender der AG Keramik, halten und den Preis überreichen.
Pressematerial der Arbeitsgemeinschaft für Keramik in der Zahnheilkunde e.V

Kontakt

Manfred Kern

AG Keramik Schriftführung

Postfach 100117

76255 Ettlingen

kern.ag-keramik@t-online.de www.ag-keramik.de 